\title{
Mais e novos imigrantes: que dificuldades para os profissionais nos Cuidados de Saúde Primários?
}

Inês Lima Maurício*

\section{RESUMO}

Com a vinda de mais imigrantes e diversificação da sua proveniência, os Cuidados de Saúde Primários e os seus profissionais são postos perante novos tipos de problemas, que decorrem, tanto das dificuldades de comunicação em contexto intercultural, quanto dos constrangimentos logísticos, como seja, por exemplo, o da falta de tempo para conduzir uma relação terapêutica que se quer eficaz.

Ir ao encontro das necessidades dos imigrantes, que estão muitas vezes em situação de vulnerabilidade social, e que têm entendimentos e formas de comunicar a saúde e a doença de modo diferente da dos profissionais de saúde, é um desafio que exige, para além de suporte institucional, competências comunicacionais, e algum conhecimento sobre diferentes culturas, religiões, crenças, usos e costumes.

O artigo propõe-se analisar algumas dessas dificuldades, sugerindo formas de abordagem que permitam a criação de serviços culturalmente adaptados, abertos a todas as convicções religiosas, e facilitadores do diálogo intercultural, conforme é recomendado pelo Alto Comissariado para a Imigração e Diálogo Intercultural.

Palavras-Chave: Imigrantes; Profissionais de Saúde; Comunicação Intercultural.

\section{INTRODUÇÃO}

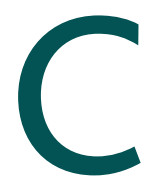

om a vinda de mais imigrantes para Portugal, abre-se um mundo de diversificação e de oportunidades, mas que requer ajustamentos a diversos níveis, tanto da parte de quem chega, como da população portuguesa e das diversas instituições nacionais.

Não pretendendo, neste espaço, discutir o fenómeno político da imigração em todas as suas vertentes, importará porém contextualizá-lo tomando como ponto de partida as questões ligadas aos Cuidados de Saúde.

Sónia Dias e Aldina Gonçalves ${ }^{1}$ reviram um conjunto de estudos, que sugerem uma maior vulnerabilidade a doenças e problemas de saúde das populações migrantes, tanto no que respeita às doenças infecciosas, como à saúde mental e reprodutiva.

*Psicóloga; Mestre em Psicologia Social e Organizacional; Professora Adjunta Equiparada na Escola Superior de Saúde de Alcoitão. Centro de Saúde da Reboleira
O efeito inverso, isto é, o da melhoria da saúde dos imigrantes, foi também encontrado em estudos que compararam os indicadores de saúde dos imigrantes no país de acolhimento com os da população do país de origem.

Estando presentes diversos factores, de ordem socio-económica e cultural, a biológicos e genéticos, as autoras concluem que a migração não é em si própria um risco para a saúde. A vulnerabilidade dos imigrantes estará associada antes a características sócio-económicas, como sejam a pobreza, as condições de trabalho e de gozo de direitos ao nível da protecção social, e a aspectos de ordem psico-social, nomeadamente aos processos de ajustamento e de aculturação, que poderão potenciar alguns riscos, como sejam o do consumo excessivo de álcool, tabaco ou drogas.

As dificuldades dos imigrantes no acesso aos cuidados de saúde têm sido alvo da atenção dos investigadores e dos governos, em ordem a conceber políticas 
que as minimizem, e que, ao mesmo tempo, ajudem a prevenir a discriminação e exclusão social.

Também a um nível nacional, assistimos a várias iniciativas governamentais e de instituições da sociedade civil, que procuram tornar mais acessível a prestação de cuidados de saúde aos imigrantes.

Gostaríamos, aqui, de referir a criação do Gabinete de Saúde do Centro Nacional de Apoio ao Imigrante em 2003, e que resultou de uma parceria entre o Alto Comissariado para a Imigração e Diálogo Intercultural ACIDI e o Ministério da Saúde. ${ }^{2}$ Este Gabinete de Saúde, para além de identificar os problemas de acesso dos imigrantes ao Sistema Nacional de Saúde, procura informá-los sobre os seus direitos e deveres, e apoiá-los em situações de carência social e de cuidados de saúde.

Se estes problemas têm vindo a ser alvo de diversas análises e de estratégias de intervenção, o mesmo não se poderá dizer das dificuldades sentidas pelos profissionais de saúde - médicos, enfermeiros e outros técnicos, postos perante a necessidade de intervir junto de imigrantes de diversas proveniências, culturas, estilos de vida, estatutos socioeconómicos e com diferentes concepções sobre a saúde e a doença.

Muitas vezes, os profissionais de saúde vêem-se a braços com diversos tipos de problemas, aos quais dão resposta de forma individual, apoiando-se no melhor das suas competências técnicas e comunicacionais. Esta gestão é possível quando o número de doentes imigrantes atendidos não é significativo, e o tipo de problemas é mais ou menos conhecido. Não se verificando estas premissas, uma vez que houve um acréscimo significativo do número de imigrantes, como veremos adiante, e, consequentemente, de utentes do Sistema Nacional de Saúde, impõe-se uma reflexão conjunta sobre os problemas mais comuns, e sobre a melhor forma de os abordar, não deixando de ter em atenção os constrangimentos de ordem legal.

\section{UMA NOVA REALIDADE}

Portugal tem uma história de imigração recente, como é referido por Mário Lages e colaboradores. ${ }^{3}$ Os autores lembram, porém, os fluxos migratórios dos cabo-verdianos nos anos 60 e 70, e também, o de pessoas provenientes das ex-colónias após as independências. Estes foram movimentos migratórios com características diferentes dos ciclos mais recentes.
É nos anos 80 que começa o segundo ciclo de imigração, que traz, como elemento novo, a diversificação da origem dos imigrantes - da Ásia, sobretudo chineses, e da América do Sul, predominantemente brasileiros, entre outros. Em 1980, dos imigrantes legais, $48 \%$ provinham de África, 31\% da Europa e 11\% da América do Sul.

Com a adesão de Portugal à Comunidade Europeia e a consequente internacionalização da economia portuguesa, verifica-se um aumento de $6,4 \%$ ao ano de imigrantes legais.

No início dos anos 90, Portugal adere ao Acordo de Schengen e verifica-se um crescimento anual de $7 \%$ de imigrantes legais, embora, no total, estes constituam apenas $2 \%$ da população. Em termos do impacto e da percepção pública, a presença dos imigrantes em Portugal é, portanto, pouco significativa, até ao ano 2000. Não tomamos aqui em atenção o impacto em pequenas localidades, até porque, como veremos adiante, a concentração destes imigrantes tende a ser no litoral e nos grandes centros urbanos do país.

Os autores não deixam de chamar a atenção para o desfasamento entre o número de imigrantes legais e ilegais, pecando os dados existentes por defeito.

A partir de 2001, há um aumento súbito de imigrantes dos países da Europa de Leste - romenos, moldavos, russos e sobretudo ucranianos. Os imigrantes dos PALOP deixam de estar no topo, para passarem a ser os brasileiros e os ucranianos.

No que respeita à escolha da área de residência, verifica-se uma distribuição assimétrica, seguindo a tendência da população portuguesa, que se concentra no litoral e nos grandes centros urbanos. Assim, os distritos de Lisboa, Porto, Setúbal e Faro acolhem 75\% dos imigrantes, estando Lisboa claramente à frente, com cerca de $45 \%$.

A partir de 2003, são Lisboa, e sobretudo Faro, que concentram o maior número de imigrantes.

Esta nova realidade tem, certamente, impacto nos Cuidados de Saúde Primários, uma vez que desde 2001 os cidadãos estrangeiros que residem legalmente em Portugal têm acesso, em igualdade de tratamento com os beneficiários do Serviço Nacional de Saúde, tanto à prestação de cuidados de saúde, como de assistência medicamentosa (Despacho no $25.360 / 200$, publicado em D.R. de 12 de Dezembro). ${ }^{4}$ No caso do imigrante 
não residir legalmente em Portugal, terá acesso aos serviços do SNS, se comprovar, através de documento passado pela Junta de Freguesia, que reside em território nacional há mais de noventa dias. Neste caso, são cobradas despesas de acordo com as tabelas em vigor, tendo em atenção a situação económica e social do doente, a aferir pelos serviços de segurança social.

\section{OS PROFISSIONAIS DE SAÚDE PORTUGUESES NA RELAÇÃO COM O «OUTRO»}

Na relação com o «outro», são investidas as competências comunicacionais, as experiências, o grau de conhecimento que dele temos, as crenças e atitudes. Quando o outro é imigrante, as normas e os padrões culturais ganham relevo, numa troca comunicacional que se quer eficaz.

Como refere Furtado de Sousa, ${ }^{5}$ apoiando-se nas afirmações de Ramos (2001), a comunicação é uma forma de aproximar culturas, sendo que a comunicação intercultural implica uma consciência da própria identidade na relação com o outro e as suas reacções à alteridade.

Não está documentado o tipo de atitudes e de valores dos profissionais de saúde em relação aos seus utentes imigrantes, nem a sua posição individual em relação às questões da imigração.

Assim sendo, tomemos como referência o estudo levado a cabo por Mário Lages e Verónica Policarpo, ${ }^{6}$ sobre as atitudes e valores da população portuguesa perante a imigração, publicado em 2003, partindo do princípio, certamente questionável, de que, sendo os profissionais de saúde na sua maioria portugueses, partilham do entendimento geral da população sobre este assunto.

Neste estudo, a aceitação e tolerância dos portugueses em relação aos imigrantes é acedida através de questionários que comportam itens, como sejam: a concordância com a vinda de mais imigrantes, a igualdade de direitos com a população portuguesa, a reunificação familiar, a segurança, a percepção de qual dos grupos é mais trabalhador e o sentimento de diferença cultural. Este sentimento de diferença cultural expressa-se na percepção que os portugueses têm, sobre o modo como os imigrantes educam os filhos, das suas crenças e práticas religiosas, valores e comportamentos sexuais, língua falada e usos e costumes.

Podemos dizer que a maioria dos portugueses dis- corda da vinda de mais imigrantes, sejam eles africanos $(74,4 \%)$, imigrantes de Leste $(73,4 \%)$, ou brasileiros (71,7\%). Discordam mais os portugueses com instrução mais baixa do que os que têm o grau de ensino superior.

Interessante é também o facto de a maioria dos portugueses referir que a convivência melhora o entendimento com os brasileiros (84,5\%), com os imigrantes de Leste $(68,4 \%)$ e com os africanos $(60,4 \%)$.

Nenhum destes grupos é percepcionado como sendo mais trabalhador que os portugueses, embora os que afirmam que sim, destaquem os imigrantes de leste como mais trabalhadores, seguidos dos africanos e por último dos brasileiros. Os autores sugerem a interferência de estereótipos sociais neste julgamento.

Na percepção das diferenças culturais acedidas através dos itens acima referidos, os africanos são sentidos como mais diferentes quanto aos usos e costumes, maneira como educam os filhos, crenças e práticas religiosas e valores e comportamentos sexuais.

Os imigrantes de leste surgem como mais diferentes apenas em relação à língua que falam.

Os brasileiros são percepcionados como mais semelhantes.

Os portugueses defendem, ainda, que os imigrantes têm de deixar os seus costumes se quiserem fazer parte da nossa sociedade (61\%). A coadjuvar esta posição, apenas $39,7 \%$ concorda que a presença de imigrantes enriquece a vida cultural do nosso país.

O grau de instrução é uma variável sensível na resposta às questões, o que leva os autores a concluir que, quanto mais instruídos, maior a aceitação e tolerância dos portugueses.

Poderemos supor, mas não afirmar, que, pertencendo os profissionais de saúde ao grupo dos portugueses mais instruídos, terão tendência a ter atitudes de maior aceitação e tolerância em relação aos imigrantes.

Independentemente da atitude individual em relação aos imigrantes, os profissionais de saúde estabelecem com os seus utentes relações de ajuda, e, em qualquer circunstância, irão intervir com este desígnio supremo de ajudar, de promover a saúde, ao abrigo de padrões éticos, deontológicos, legais e técnicos ( $\mathrm{n}^{\circ} 1$ do artigo $6^{\circ}$ e artigo $26^{\circ}$ do Código Deontológico da Ordem dos Médicos; artigo 81ํ do Código Deontológico da Ordem dos Enfermeiros). ${ }^{7,8}$ 


\section{SABEMOS QUAIS SÃO AS DIFICULDADES DOS PROFISSIONAIS DE SAÚDE NA SUA RELAÇÃO COM OS IMIGRANTES?}

Se fizermos esta pergunta a um conjunto de profissionais de saúde dos Cuidados Primários, de modo aleatório, iremos, provavelmente, obter algumas respostas inesperadas, mas também algumas invariantes. Qual a sua representatividade, e qual o peso dessas dificuldades ao nível do seu desempenho, é outra questão que é certamente pertinente para a escolha de estratégias e de políticas de saúde promotoras de mudança positiva, no sentido de uma maior eficiência. Impõe-se, pois, um estudo futuro, que dê resposta, entre outras, a estas duas questões.

Na ausência de um estudo deste tipo, e face à necessidade de reflectir sobre este tema, decidimos fazer o exercício de inquirir, através de pergunta aberta, alguns profissionais de saúde a trabalhar nos Cuidados Primários. Ficamos limitados aos nossos conhecimentos pessoais, e a duas áreas geográficas: Damaia e Moita.

Conscientes que estamos da ausência de rigor metodológico (que ficará para o futuro estudo acima sugerido), este inquérito informal permitiu, ainda assim, aceder a alguns problemas sentidos pelos profissionais entrevistados.

Comecemos por enunciar as dificuldades que foram referidas, sem ordem de valor ou frequência de resposta. Assim, identificámos como fonte de dificuldades:

1. A língua diferente.

2. As diferenças culturais, e, mais especificamente, os usos e costumes, os constrangimentos religiosos, mitos, tabus e crenças dos imigrantes.

3. Pedidos feitos aos profissionais e que são sentidos como não razoáveis, no contexto cultural, e de prática comum no sistema de saúde e legislativo português.

4. Diferente concepção de saúde e de doença entre os profissionais de saúde e os imigrantes.

5. Utilização, em simultâneo, da medicina tradicional.

6. Falta de recursos económicos dos imigrantes.

7. O desconhecimento, por parte dos imigrantes, sobre o funcionamento dos serviços de saúde e também da lei.

8. Dificuldades logísticas dos próprios Centros de Saúde, como sejam o grande número de imigrantes sem médico de família, o que dificulta um melhor conhe- cimento do contexto sócio cultural do imigrante;

9. A falta de tempo para uma relação, que implica maior disponibilidade do profissional.

Em relação à língua, os problemas mais comuns referem-se à ausência de intérprete, quando o utente não fala português. Quando é um familiar a fazer a tradução, por vezes também este domina mal a língua, o que foi referido para o caso de alguns imigrantes chineses e para alguns africanos.

Além disso, o recurso a um familiar como intérprete pode não garantir uma comunicação eficaz, na medida em que poderá ser perdida ou acrescentada informação na tradução que é feita para o paciente, e deste para o profissional de saúde. Isto acontece, por um lado, porque não sendo um tradutor profissional, o familiar está mais sujeito a cometer erros, e por outro, porque, questões da ordem da relação e da cultura, poderão levar à distorção dos conteúdos. Estes factores relacionais podem afectar o próprio doente e levá-lo a não se sentir confortável em fornecer algumas informações na presença do seu familiar.

Por outra ordem de razões, na presença de um intérprete que não seja seu familiar, o doente pode sentir-se igualmente constrangido, em face de determinados assuntos mais delicados, pelo que é sempre necessário que ele manifeste o seu consentimento no uso deste recurso. A necessidade de estabelecer uma comunicação que permita uma correcta intervenção clínica e o respeito pela privacidade do doente, nestas circunstâncias, é, em si próprio, um exercício de equilíbrio, nem sempre alcançável.

Considerando, ainda, o caso dos africanos provenientes de países de expressão inglesa ou francesa, mas cujo domínio dessas línguas é, ele próprio, fraco, mesmo que o profissional de saúde as conheça, fica sempre a dúvida se a recolha de informação para chegar a um diagnóstico foi correcta e/ou se as prescrições foram entendidas.

A dificuldade em comunicar em português é também sentida na relação com alguns migrantes dos PALOP, que falem preferencialmente os seus dialectos, $\mathrm{e}$ que residam há menos tempo em Portugal.

Estas dificuldades de comunicação exigem um dispêndio de tempo maior para cada consulta, o que não terá um impacto significativo quando o número de consultas a imigrantes que falem outras línguas é reduzi- 
do. Nem sempre será esse o caso, sobretudo nos distritos de Lisboa, Setúbal e Faro, onde a concentração de imigrantes é maior.

Se o imigrante percebe melhor um dialecto indígena, é de equacionar um pedido de ajuda à embaixada ou consulado do país de origem do doente, embora esta decisão deva ser ponderada em função também da sua concordância.

É, também, possível utilizar o Serviço de Tradução Telefónica do Alto Comissariado para a Imigração e Diálogo Intercultural, como propõem Silva e Martingo. ${ }^{9}$ Este serviço foi criado no seguimento da adopção das recomendações do projecto europeu «Migrants -Friendly Hospitals», referido pelos autores, e que tem por objectivo tornar as instituições de saúde «amigáveis» para os imigrantes.*

Silva e Martingo ${ }^{9}$ sugerem, ainda, a celebração de protocolos com associações de imigrantes, para que estas possam ajudar quando a língua é um obstáculo, desde que os mediadores estejam preparados para a mediação da interpretação clínica. Em alguns casos, estes mediadores poderão, eles próprios, ser profissionais de saúde que ainda não tenham obtido equivalência dos seus cursos em Portugal.

Em qualquer dos casos em que seja necessário o recurso a intérpretes, é necessário garantir que estes tenham tido formação e que estejam bem cientes das suas responsabilidades, no que ao sigilo profissional diz respeito.

Fonseca e colaboradores, ${ }^{10}$ apoiando-se num estudo de Fonseca e col. (2005), concluem que são os imigrantes dos PALOP $(63,6 \%)$ o grupo que utiliza com mais frequência o sistema nacional de saúde. As comunidades brasileira e de cidadãos de Leste que se instalaram há menos tempo e que têm um grande número de ilegais, apenas recorrem aos serviços em situação de urgência. A autora sugere que, no caso dos imigrantes de Leste, a língua pode ser o factor impeditivo. Neste grupo, apenas $44 \%$ dos inquiridos no estudo são utentes de Centros de Saúde.

O recurso a intérpretes, não sendo uma solução perfeita, é necessária, devendo ser equacionada caso a caso por cada Centro de Saúde, em função do número de

*A informação sobre o funcionamento desta linha pode encontrar-se no seguinte endereço: http://www.acidi.gov.pt/ utentes que falam determinada língua, da relação custo/beneficio, da programação das consultas, entre outros aspectos de carácter logístico.

No que às diferenças culturais, usos e costumes, constrangimentos religiosos, mitos, tabus e crenças dos imigrantes diz respeito, parece lógico que o desconhecimento destes aspectos, por parte do profissional de saúde, é uma barreira que se põe já no momento de recolha das queixas, mas também, ao nível das soluções terapêuticas propostas.

A própria limitação ao exame clínico, no que respeita, por exemplo, à exposição do corpo, constitui um constrangimento. Por vezes, é possível ultrapassá-lo, garantindo a escolha de um profissional do mesmo sexo do do doente. Proceder a um exame objectivo, que possa ser mal aceite em função das diferenças culturais, poderá exigir a presença de um familiar ou de outro profissional na sala, o que recoloca as questões acima equacionadas, a propósito do uso de intérpretes.

A presença do familiar ou do técnico com funções específicas e que possa ter, até, um papel de mediação, poderá, de igual modo, contribuir para a salvaguarda da integridade profissional dos técnicos, e do modo como ela é entendida.

Podemos, no entanto, questionar até que ponto um Centro de Saúde se deverá adaptar, para dar resposta a todas as necessidades destes utentes. Como vimos, $61 \%$ dos portugueses acha que os imigrantes deverão deixar de lado os seus costumes para fazerem parte da nossa sociedade, pelo que esta posição poderá constituir-se numa barreira à tomada de decisão, no sentido de tornar os cuidados primários mais amigáveis para os imigrantes.

Tendemos, no entanto, a achar que esta é também uma decisão de gestão de recursos, que deverá encontrar um compromisso entre os custos acrescidos de determinadas medidas e a necessidade de não comprometer a acessibilidade dos imigrantes aos cuidados de saúde, preconizada na lei portuguesa.

As recomendações do Alto Comissariado para a Imigração e Diálogo Intercultural vão no sentido da criação de serviços culturalmente adaptados, abertos a todas as convicções religiosas, e facilitadores do diálogo

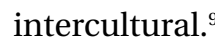

A maior parte destas considerações são de ordem institucional. Na dimensão da relação individual, cada 
profissional de saúde investe a sua predisposição para tentar compreender, conhecer e comunicar de modo aberto e disponível, ao mesmo tempo que luta com as suas próprias dificuldades para o conseguir.

Consideramos que todo o processo de estabelecimento de uma relação tem um potencial de crescimento. Assim, a disposição mostrada ao utente de que, estando consciente das diferenças, se está, também, disposto a conhecê-las, não sendo condição suficiente, é condição necessária ao desenvolvimento dessa relação.

Há aqui espaço para uma análise introspectiva individual, de cada profissional de saúde, sobre os seus próprios preconceitos, dificuldades e competências, no estabelecimento de uma relação clínica intercultural.

Um conhecimento de usos e costumes prévio poderia evitar momentos de embaraço de parte a parte. Alguma informação a este nível do conhecimento de outras culturas poderá ajudar nos casos mais comuns. O Alto Comissariado para a Imigração e Diálogo Intercultural disponibiliza, no seu site, publicações online de estudos, teses, revistas, conferências e outras iniciativas, que pode ser uma fonte de recolha de informação interessante.

Por vezes, são feitos pedidos aos profissionais que não são sentidos como razoáveis, no contexto cultural, e de prática comum no sistema de saúde e legislativo português.

Ora, se é verdade que o entendimento das «razões» do outro é fundamental para a modulação da relação, nem sempre, porém, este entendimento permite ao profissional de saúde ir ao encontro dos pedidos e expectativas dos imigrantes. A título de exemplo, referimos aqui alguns pedidos insistentes de alguns grupos de imigrantes, para a prescrição de exames complementares de diagnóstico que não são compatíveis com o quadro clínico. Esta dificuldade foi referida por mais do que um dos profissionais por nós inquiridos inicialmente através de pergunta aberta, que a interpretam como resultado de um eventual mecanismo de tranquilização em situação de vulnerabilidade social como é o da imigração, decorrente de hábitos alicerçados na diferente organização dos serviços de saúde nos países de origem, ou, ainda, com a diferente percepção cultural, do que é uma «boa» intervenção clínica.

O esforço adicional a desenvolver pelo clínico neste caso, passa pela explicação ao doente, do funcionamento dos serviços, e pelo fornecimento de um quadro compreensivo do que se está a passar ao nível das suas queixas. No fundo, é um esforço de redução da ansiedade do doente.

Foi, também, referido o pedido de circuncisão dos filhos por motivos religiosos, por parte de pais imigrantes africanos. A abordagem deste pedido é, em si própria, multidimensional. Por um lado, esta intervenção não é isenta de riscos quando levada a cabo em situações precárias. Por outro, não havendo patologia subjacente, não haverá justificação clínica para tal intervenção. Mesmo tomando como boa a razão da intervenção por motivos religiosos e culturais, poderemos questionar se o estado deverá comparticipar estas cirurgias, ou ainda, colocá-las em listas de espera, que já de si são longas. A resposta a estas questões remete-nos para uma dimensão de tomada de decisão ao nível das políticas de saúde, que limitam e enquadram o exercício dos profissionais.

Estes imigrantes normalmente têm dificuldade em aceitar uma intervenção cirúrgica programada, mesmo quando aconselhados a procurar uma instituição de saúde privada, pois têm a expectativa de resolver o seu problema no momento do pedido.

Nestes dois exemplos, apesar de tudo, o profissional de saúde pode apoiar-se em normas de funcionamento do Sistema Nacional de Saúde, e em orientações técnicas, para comunicar a sua posição, e aconselhar.

Consideramos, também, que a troca de experiências entre pares ajuda a assegurar do bom julgamento nas tomadas de posição em situações pouco comuns, ou comuns, mas fora dos requisitos da prática clínica, assim como ajudará a ponderar outras alternativas de intervenção.

Apesar de a maioria dos profissionais com quem falámos referir a falta de tempo como problema da sua prática quotidiana, faria sentido criar um espaço de partilha mais ou menos estruturado, mais ou menos frequente, de modo a promover práticas comuns e maior conforto na acção. Este nível de conforto é importante para aumentar a disponibilidade de cada profissional para se envolver em relações que põem outro tipo de exigências.

Alicerçada nas diferenças culturais, surge a diferente concepção de saúde e de doença entre os profissio- 
nais de saúde e os imigrantes, que traz dificuldades à relação entre ambos. Estas diferenças, embora tendam a esbater-se na segunda e terceira geração, podem, ainda, existir em filhos e netos de imigrantes, o que implica manter o vector cultural na mira do profissional de saúde.

As representações sociais de saúde e de doença é um tema que está amplamente estudado, como nos referem Reis e Fradique. ${ }^{11}$

«Podem tirar-se duas conclusões relevantes destes estudos: primeiro, as significações das pessoas sobre o estado de saúde estão intimamente ligadas a significações mais latas sobre si próprias, sobre o mundo e a vida e imbuídas em sistemas culturais locais; segundo, as significações leigas diferem em larga medida das significações médicas ou dos profissionais de saúde, mas coexistem e competem com estas.»

Reis, ${ }^{12}$ reflectindo sobre a concepção de processos de saúde e de doença entre leigos e médicos, refere que eles entram, por vezes, em conflito. A saúde é, também, definida num contexto mais amplo de relação da pessoa com os seus ambientes físicos, profissionais e de relacionamento interpessoal, e mais próximo do modelo biopsicossocial. Este autor considera, pois, fundamental ter em conta dimensões mais amplas de entendimento do conceito de saúde.

Furtado de Sousa, ${ }^{5}$ citando Weinman e Ogden (1999), assinala que «os técnicos de saúde têm crenças pré-existentes sobre a prevalência e incidência de cada problema de saúde e estas crenças influenciam o processo de desenvolvimento das hipóteses».

Também Helman ${ }^{13}$ constata que a concepção de saúde e de doença entre os médicos e os seus pacientes diferem, mesmo que estes partilhem a mesma cultura. Isto porque as suas perspectivas apoiam-se em diferentes premissas. Para este autor, o modelo da medicina moderna tendencialmente põe maior ênfase na descoberta e quantificação de dados físico-químicos, não enfatizando os factores menos mensuráveis, como sejam os sociais e emocionais.

A explicação dos leigos para a etiologia das doenças tende a situar-se na esfera do social ou sobrenatural, nas comunidades do mundo não industrializado, e na esfera natural ou centrada no paciente, nas sociedades ocidentais industrializadas.

Quando centrada no paciente, a doença é percepcio- nada como resultado do mau funcionamento do corpo, por vezes relacionado com mudanças na dieta ou dos comportamentos, estilos de vida, etc. Há, assim, espaço para uma responsabilidade individual no estado de saúde, atitude encorajada no mundo ocidental.

As causas naturais de origem inanimada ou de organismos vivos (microrganismos, vírus, animais, plantas) comportam, ainda, os aspectos ambientais, como sejam as alterações climáticas ou a poluição.

Quando a etiologia da doença é atribuída à esfera social, refere-se à influência dos outros, à sua malevolência ou mau-olhado, e tende a verificar-se em comunidades pequenas e onde o conflito interpessoal é frequente.

Quanto às causas sobrenaturais, a doença resulta de acções directas de deuses ou espíritos, e acontece quando a vítima é culpada de comportamentos anti-sociais, imorais, ou blasfemos. Estas causas não são mutuamente exclusivas.

O autor refere ainda que, do ponto de vista do paciente, e em determinadas culturas, o estar doente tem muitas vezes componentes psicológicas, morais e sociais, que estão associadas a outros tipos de adversidade na sua vida. Em todas as sociedades há «convenções» sobre comportamentos a adoptar em presença da doença, o que dá algum controlo ao doente sobre o modo como a comunica.

Tanto a representação da doença, como o modo como ela é percebida pelos outros é determinada por factores socioculturais e religiosos.

Como nos diz Glick, ${ }^{14}$ na medicina ocidental a causa das doenças não tem uma relação essencial com o contexto sociocultural, ao passo que na maioria dos outros sistemas medicinais a causa e o contexto estão intimamente ligados. Assim sendo, os tratamentos reflectem as ideias expressas no diagnóstico. Se este se apoiar no poder de fontes malignas, então os tratamentos deverão tentar restabelecer o equilíbrio de poderes entre a vítima e as referidas fontes. Isto poderá ser feito fortalecendo a vítima (através de processos homeopáticos ou de remédios caseiros), ou enfraquecendo o antagonista («mobilizando» fontes benévolas), ou ambas em simultâneo.

Outro aspecto interessante, e que é referido por Helman, ${ }^{13}$ por exemplo, é o da percepção da gravidade da doença em diferentes culturas, que depende das con- 
dições de trabalho e do custo do tratamento.

Em concordância com esta afirmação, registámos que os nossos inquiridos assinalaram como um problema na relação com os doentes imigrantes, o recurso, em simultâneo, às «medicinas tradicionais» e a falta de recursos económicos dos imigrantes. Estes dois factores poderão estar na origem de uma procura tardia de cuidados de saúde, e na dificuldade do paciente em seguir as prescrições médicas, o que atrasa a sua recuperação. Nestes casos, devem ser mobilizados os Serviços de Segurança Social, conforme recomendação constante do Despacho $n^{\circ} 25.360 / 2001 .{ }^{4}$ Este processo, porém, pode não ser compatível com a necessidade de intervenção em tempo útil, o que se afigura difícil de contornar. Resta o recurso a instituições de solidariedade social, que serão mais ou menos difíceis de mobilizar, e, em todo o caso, exigindo dispêndio de tempo.

Como nos referem Dias e Gonçalves, ${ }^{1}$ os imigrantes têm tendência a manter as práticas de saúde dos países de origem nos países de acolhimento, que se vão alterando conforme o tempo de permanência no país vai aumentando. De igual modo, quanto maior for o grau de alfabetização, maior a procura dos serviços de saúde.

Se o imigrante procura ajuda para resolver o seu problema num Centro de Saúde, está, tacitamente, a submeter-se a todo um sistema que ele sabe ser diferente do seu, o que não significa que ele esteja preparado par abdicar das suas referências. Ora, como defende Helman, ${ }^{13}$ para que a consulta seja bem sucedida, tem de haver um consenso entre as duas partes sobre a etiologia, o diagnóstico, o processo envolvido, o prognóstico e o tratamento ideal. A procura de um consenso tem de se apoiar num processo de negociação.

Em virtude da sua formação e do estatuto social, os técnicos de saúde são investidos de um determinado tipo de poder de influência que lhes permitirá, nalguns casos, aproximar os doentes do seu ponto de vista.

Tomando, no entanto, em atenção as considerações expostas sobre as diferentes representações de saúde e de doença em diferentes contextos culturais, e também, entre leigos e os profissionais de saúde, torna-se claro que esta negociação é um processo complexo, que pode, por vezes, requerer a intervenção de mediadores formados para o efeito, como sugerem Silva e Martingo. ${ }^{9}$

O desconhecimento por parte dos imigrantes sobre o funcionamento dos serviços de saúde e também da lei, poderá ser melhorado fornecendo informação em brochuras escritas na língua do imigrante, e disponíveis em lugares estratégicos do Centro de Saúde. Esta proposta não cobre todas as necessidades, mas é considerada uma boa prática. ${ }^{2,9}$

As dificuldades logísticas dos próprios Centros de Saúde, como sejam o grande número de imigrantes sem médico de família, leva a que eles sejam vistos por diferentes médicos, o que duplica o esforço de compreensão do seu contexto sócio cultural e dos padrões de comunicação do doente.

Se tivéssemos de destacar um factor em detrimento dos outros, dos referidos pelos profissionais por nós inquiridos, seria o da falta de tempo, já que foi mencionado por todos eles, sem excepção. Todos reconheceram que uma consulta a um imigrante é mais exigente do ponto de vista comunicacional, pelas razões acima analisadas, e que consome mais tempo.

\section{CONCLUSÃO}

Naturalmente, não pretendemos que as dificuldades aqui referidas e as propostas de abordagem feitas esgotem o tema, mas que este artigo seja um contributo para a reflexão que se impõe, face ao acréscimo do número e da proveniência dos imigrantes atendidos nos Cuidados de Saúde Primários.

Sabemos que uma relação terapêutica assenta em competências comunicacionais, e, como nos dizem Butler e Rollnick, ${ }^{15}$ referindo-se aos médicos e ao espaço da consulta, estes deverão ser criativos na aproximação ao mundo dos doentes, e ajudá-los a tomar o controlo da sua saúde segundo formas que são significativas para cada um deles.

Estes autores defendem que diferentes abordagens funcionam melhor para diferentes doentes e que o envolvimento do doente nas decisões tomadas melhora a adesão ao tratamento.

A comunicação em saúde, como nos refere Carvalho Teixeira, ${ }^{16}$ ocorre em contextos muito diferentes, desde a prevenção à intervenção em situações de risco, e na relação mais directa dos técnicos de saúde com os seus utentes. $\mathrm{O}$ autor defende um aumento de formação ao nível das competências de comunicação, quer na formação académica como pós-graduada e profissional. Os conteúdos desta formação comportariam as técni- 
cas básicas de comunicação, tais como a escuta activa, perguntas abertas e técnicas facilitadoras; treino assertivo; resolução de conflitos e negociação, entre outras.

Estas sugestões gerais parecem-nos ainda mais pertinentes quando a relação clínica ocorre num contexto intercultural.

Como nos diz Furtado de Sousa, ${ }^{5}$ o respeito pela diferença implica uma negociação informal, uma modulação da relação e do cuidado prestado. Exige mais do que um Saber e Saber-fazer, exige um Saber-ser.

\section{REFERÊNCIAS BIBLIOGRÁFICAS}

1. Dias S, Gonçalves A. Migração e saúde. Migrações: Revista do Observatório da Imigração 2007; 1: 15-26.

2. Horta R, Carvalho A. O gabinete de saúde do centro nacional de apoio ao imigrante: uma estratégia de acesso dos imigrantes aos cuidados de saúde. Migrações: Revista do Observatório da Imigração 2007; 1: 179-86.

3. Lages MF, Policarpo VM, Marques JC, Matos PL, Homem J. Os imigrantes e a população portuguesa: imagens recíprocas - análise de duas sondagens. Lisboa: Observatório da Imigração/ACIME; 2006.

4. Despacho $n^{\circ} 25.360 / 2001$, de 12 de Dezembro. Diário da República nº 286 - Série II.

5. Sousa JF. Os imigrantes ucranianos em Portugal e os cuidados de saúde. Lisboa: Observatório da Imigração/ACIME; 2006.

6. Lages MF, Policarpo V. Atitudes e valores perante a imigração. Lisboa: Observatório da Imigração/ACIME; 2003.

7. Código Deontológico da Ordem dos Médicos. Disponível em: http://www.ordemdosmedicos.pt/ [acedido em 19/02/2009].

8. Código Deontológico do Enfermeiro. Dec-Lei, 104/98, de 21 de Abril.
Diário da República n 93 - Série I, Parte A - artigo 81º. p. 1274.

9. Silva A, Martingo C. Unidades de saúde amigas dos migrantes - uma resposta ao desafio da multiculturalidade em Portugal. Migrações: Revista do Observatório da Imigração. 2007; 1: 155-60.

10. Fonseca ML, Esteves A, McGarigle J, Silva S. Saúde e integração dos imigrantes em Portugal: uma perspectiva geográfica e política. Migrações: Revista do Observatório da Imigração 2007; 1: 27-52.

11. Reis J, Fradique F. Significações leigas de saúde e de doença em adultos. Análise Psicológica. 2004 set; 2 (3): 475-85.

12. Reis J. O Sorriso de Hipócrates: a integração biopsicossocial dos processos de saúde e doença. Lisboa: Vega; 1998.

13. Helman CG. Culture, health and illness: an introduction for health professionals. 2nd ed. Oxford: Butterworth-Heinemann; 1990.

14. Glick LB. Medicine as an ethographic category: the Gimi of the New Guinea Highlands. In: Landy D, editor. Culture, disease, and healing: studies in medical anthropology. New York: Macmillan Publishers; 1977. p. 58-70.

15. Rollnick S, Butler C. Compliance. Rapid Reference Series. London: Mosby; 2003.

16. Teixeira JA. Comunicação em saúde: relação técnicos de saúde - utentes. Análise Psicológica 2004 Set; 22 (3): 615-20.

\author{
ENDEREÇO PARA CORRESPONDÊNCIA \\ Inês Lima Maurício \\ Centro de Saúde da Reboleira \\ Praça Conde da Lousã - Damaia \\ 2720-122 Amadora \\ Tlm: 934698282 \\ E-mail: bartines@ip.pt
}

Recebido em 22/12/08

Aceite para publicação em 16/02/09

\section{ABSTRACT}

With the arrival of an increasing number of immigrants from different origins, primary health care and its professionals are facing new types of problems that derive from the difficulties of communication widespread on intercultural contexts and also from logistics restrictions, such as lack of time to conduct an effective therapeutic relationship.

Responding to the needs of the immigrants - which are most of the time socially vulnerable and have ways of understanding and expressing their health and disease-related concerns that differ from those of the health professionals - is a challenge that asks for institutional support, communication qualifications and some knowledge about different cultures, religions, beliefs and habits.

The purpose of the article is to analyze some of those difficulties, suggesting ways of approach which allow for the creation of services that are culturally adapted, open to all the religious believes and that facilitate the intercultural dialog, as recommended by the High Commissioner for Immigration and Intercultural Dialogue.

Keywords: Immigrants; Health Professionals; Intercultural Communication. 